\title{
PASSING THE BATON: AN EXPERIMENTAL STUDY OF SHIFT HANDOVER
}

\author{
Bonny Parke, Ph. D., Alan Hobbs, Ph. D. \\ SJSURF/NASA Ames Research Center \\ Barbara Kanki, Ph. D. \\ NASA Ames Research Center
}

\begin{abstract}
Shift handovers occur in many safety-critical environments, including aviation maintenance, medicine, air traffic control, and mission control for space shuttle and space station operations. Shift handovers are associated with increased risk of communication failures and human error. In dynamic industries, errors and accidents occur disproportionately after shift handover. Typical shift handovers involve transferring information from an outgoing shift to an incoming shift via written logs, or in some cases, face-to-face briefings. The current study explores the possibility of improving written communication with the support modalities of audio and video recordings, as well as face-to-face briefings. Fifty participants participated in an experimental task which mimicked some of the critical challenges involved in transferring information between shifts in industrial settings. All three support modalities-face-to-face, video, and audio recordings, reduced task errors significantly over written communication alone. The support modality most preferred by participants was face-to-face communication; the least preferred was written communication alone.
\end{abstract}

\section{INTRODUCTION}

In dynamic working environments such as hospitals, air traffic control centers and maintenance facilities, errors and accidents occur disproportionately after shift handover (Parke \& Kanki, 2008). Several high profile industrial accidents, such as the Piper Alpha oil platform disaster and the Sellafield radiation leak resulted in part from inadequate shift handovers (Cullen, 1990; Lardner, 2000). The accident of Continental Express Flight 2574 in 1991 has become a much-cited example of the dangers of faulty shift handovers. The aircraft crashed near Eagle Lake, Texas, killing all 14 people on board. A row of fasteners for the left horizontal stabilizer leading edge had been removed and not replaced during maintenance the night before the accident. The NTSB found that the error might have been detected had shift handover procedures between outgoing and incoming shifts been followed (NTSB, 1991).

Higher error rates also occur in American and Canadian Air Traffic Control in the period after position relief briefings (Stager \& Hameluck, 1988). A quarter of all operational errors were found to have occurred in the first 15 minutes after position relief briefings in Air Route Traffic Control Centers (ARTCCs) and Terminal Radar Control facilities (TRACONs) (Della Rocco, Cruz, \& Clemens, 1999). It is also likely that there are more serious consequences to communication errors occurring between shifts than occurring within shifts. Parke and Kanki (2008) found this to be the case in a recent study using ASRS aviation maintenance incident reports.

Aviation maintenance provides a supreme test of the handover process. The task itself has many opportunities for error, and sometimes twelve to fifteen shifts work on trouble-shooting and resolving a problem. All the while, detailed records have to be kept on each part and each change to the aircraft, since the consequences of error can be severe. Paperwork is a critical aspect of aviation maintenance, and documentation forms the basis of much information transfer between shifts (Parke and Kanki, 2008).

In considering collaborative media, Baltes, Dickson, Sherman, Bauer, and LaGanke (2002) note that media differ in the extent to which they provide synchronous communication, and the extent to which non-verbal cues can be transmitted. Much of the literature on collaborative media has focused on synchronous communication, where geographically separated participants communicate in "real time" (Wainfan \& Davis, 2004). As a synchronous communication method, face-toface handovers enable the incoming worker to ask questions and rephrase the material to be handed over, so as to expose differences in mental models (Grusenmeyer, 1995; Leavitt \& Mueller, 1962; Lardner, 2000) Furthermore, face-to-face handovers enable gestures, eye contact, tones of voice, degrees of confidence, and other redundant and rich aspects of personal communication to be utilized in conveying possible different mental models (Hopkin, 1980; Knapp, 1995). Faceto-face handovers with written support have been shown to reduce errors in aviation maintenance compared to written handovers with verbal communication filtered through a supervisor (Eiff, Lopp, Nejely, \& Vice, 2001). Face-to-face handovers with written support are standard operating procedures in many high-risk domains, e.g. in nuclear power plants (U.S. Dept. of Energy, 1998), and air traffic control (FAA, 2001). Hour long face-to-face handovers with written support are scheduled for mission control for both the Shuttle and the International Space Station (Patterson \& Woods, 2001). 
Despite the undoubted advantages of face-to-face briefings with written support, for a variety of logistical and economic reasons, maintenance handovers usually involve nonsynchronous communication, where the participants communicate across a time gap using documentation such as paper logs, without the advantages of feedback and non-verbal cues. A range of approaches have been proposed to improve the quality of shift handovers. Recorded visual and auditory messages offer the ability to augment handover documentation with non-verbal cues and/or spatial information. The objective of this study was to evaluate, under controlled conditions, the effectiveness of audio, audio-visual (video), and face-to-face support modalities on traditional paper-based handovers, and to determine the strengths and vulnerabilities of each modality.

\section{METHOD}

An experimental task was created to reproduce some of the challenges of maintenance. The task involved the "repair" of hardware comprising sets of bolts, nuts, and washers, inspired by Reason's (1997) observation that if a bolt is fitted with eight nuts, there is only one way to disassemble it, but over 40,000 potential ways to re-assemble it incorrectly. The task was designed so that each participant could not complete a repair in their allotted time, but must hand over a set of partially completed repairs to the next participant.

On the basis of the literature on collaborative media and shift handover, we hypothesized that face-to-face communication would produce the fewest errors in the maintenance task and that participants would show a preference for face-to-face communication. Of critical interest was how the addition of audio and video information would change the nature of intershift communication in cases where face-to-face communication was not possible. Our hypothesis was that by permitting participants to augment traditional paper handover documentation with voice recordings and (in the case of video) spatial information, the effectiveness of handovers would be improved over handovers in which traditional paper documents were the only means of communication.

\section{Participants and Study Design Overview}

Fifty participants were recruited from the surrounding urban community via a website that contained job listings. Subjects were paid for participating in the study. Ten experimental trials were run, each with five participants. The study was a repeated-measures design, with each of five participants rotating sequentially through the conditions, each located in a separate room. Each room was equipped to provide a different type of handover. The same amount of time was allotted in each condition for preparing/giving handovers. To improve face validity, each condition was associated with a specific space or aviation theme, such as the Boeing 747 or the International Space Station. The themes were rotated between rooms. Participants filled out questionnaires and were debriefed after the experiment. Videos of all sessions were captured digitally for more detailed analysis with Watchdog ${ }^{\mathrm{TM}}$ software, Logitech ${ }^{\mathrm{TM}}$ webcams, and the institutional intranet. This also enabled real time monitoring of the experiment in multiple rooms on a single monitor.

\section{Materials}

Each test room contained a computer with a screen and a mouse, and, as shown in Figure 1, the following experimental materials:

(1) An instruction card containing the text shown in Table 1.

(2) Eight large bolts consisting of four sets of two bolts each. Each bolt was fitted with between five and eight nuts and washers in a pre-determined sequence. Each nut and washer was labeled with a unique serial number. Approximately $25 \%$ of the nuts and washers were marked with red paint on the inside surface, to indicate corrosion. Corrosion was only visible once the nut or washer was removed from the bolt. (3) A 32 page "Replacement Parts Manual" listing each part in numerical order with its corresponding replacement part number. The parts were listed in five different date ranges, requiring participants to search the date ranges before locating the part number that was linked to its corresponding replacement part number.

(4) Spare parts bins containing replacement nuts and washers, each labeled with a serial number.

\section{Procedure}

The nature of the experimental task was outlined and Institutional Review Board consent forms were signed during a pre-briefing. Then participants were given an opportunity to practice the task and use the video and audio support modalities.

Each participant worked alone in a room with the experimental materials. At the beginning of each "shift," each participant activated a timer displayed on the computer screen. They then inspected nuts and washers for "corrosion." If corrosion was found, the part was removed and the participant referred to the Replacement Parts Manual to identify the appropriate replacement part. The task was designed to ensure that participants could not remove and replace a part in one shift. Therefore the new replacement part was set aside to be approved during the break between shifts. Only approved parts could be installed on bolts. The timer counted down from 10 minutes and, at the end of this period, the participant received a signal to stop working and rate the task on degree of difficulty, confusion, frustration, and the adequacy of the information that had been handed to them at the beginning of the shift. Each assessment was made using a five point Likert scale. Participants then had five minutes to prepare/give a briefing for the next participant, who was required to continue the task, taking it up at the point where the earlier participant had left it. After each participant completed this procedure in 
one room, they went on to the next room where a different briefing modality awaited them.

The different modalities were as follows: (1) paper alone, in which the participant made written notes to be left for the next participant, (2) paper and audio, in which in addition to written notes, an audio recording was made, (3) video and paper, in which in addition to written notes, a video recording with sound was created for the next participant, (4) face-toface and paper, in which in addition to written notes, the departing and arriving participant could communicate directly about the status of the task, and (5) a "cues alone" or no handover (control) condition, in which departing participants were not permitted to leave information for the arriving participant, other than positioning the experimental materials, which could potentially convey some information.

At the completion of the experiment, the progress of the bolt replacement work in each room was evaluated, and the number of bolts with errors was counted. Errors consisted of those bolts which had been manipulated but not completed correctly--that is, replaced parts were present but in the wrong order, parts were absent, or incorrect parts were present.

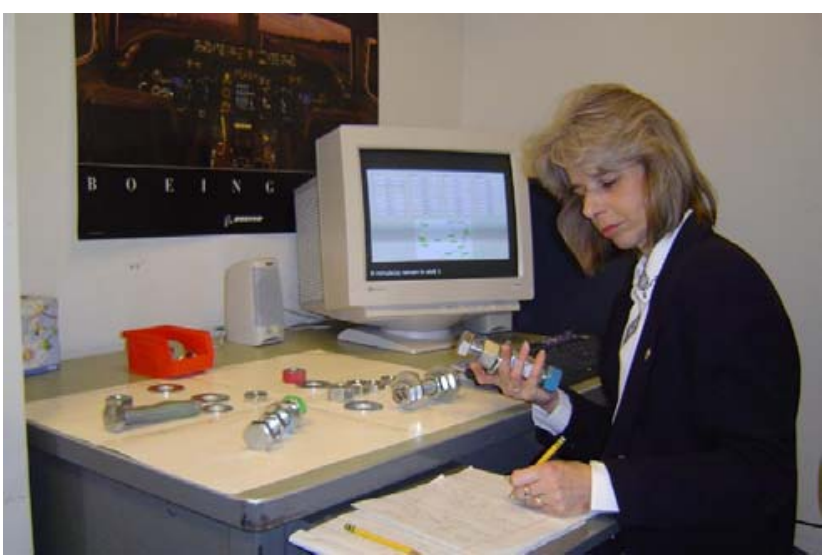

Figure 1. The experimental task involved the removal and replacement of nuts and washers on bolts.

Table 1. Participant Instruction Sheet

\begin{tabular}{l}
\hline 1) Choose a bolt pair to work on. \\
2) Identify a corroded part. So that you can find its \\
replacement, note the part number. \\
\hline 3) Using this number, look in the Replacement Part \\
Manual for the replacement part number. \\
\hline 4) Using the replacement part number, find the \\
replacement part in the Spare Parts bin. \\
\hline 5) Put the replacement part in the ziplock bag labeled \\
"PENDING APPROVAL" and write on the outside the \\
number of the part that is in the bag. Put the ziplock \\
with the part in the "PENDING APPROVAL" bin. The \\
new part will be approved between shifts. \\
6) Identify the corresponding stressed part on the \\
adjacent bolt, and note its part number. Follow steps 3 \\
to 5 above.
\end{tabular}

7) The next shift will have to physically replace the corroded or stressed part with the approved part and put the corroded or stressed part in the "Faulty Parts" bin.

\section{RESULTS}

The dependent variables reported here are: errors, number of communication acts, rated ease of giving and receiving handovers, and rankings of most preferred handovers. The data were analyzed with repeated measures ANOVAs. In the figures below, error bars around the means are the $95 \%$ confidence intervals.

\section{Errors in the Different Handover Conditions}

As can be seen in Figure 2, the paper alone condition had the most bolts with errors. In this condition, an average of 6.2 bolts out of 8 were completed incorrectly, compared to an average of 3.5 bolts completed incorrectly in the face-to-face condition $(M \mathrm{~s}=3.6,4$, and 4.8 respectively for video, audio and cues alone condition). The paper alone condition had significantly more errors $(p<.01)$ than all of the other conditions, except for the cues alone condition where no handover materials were provided and information was gleaned from the position of bolts, nuts, and washers alone $(M S=12.52, F(4,36)=3.67, p=.013)$.

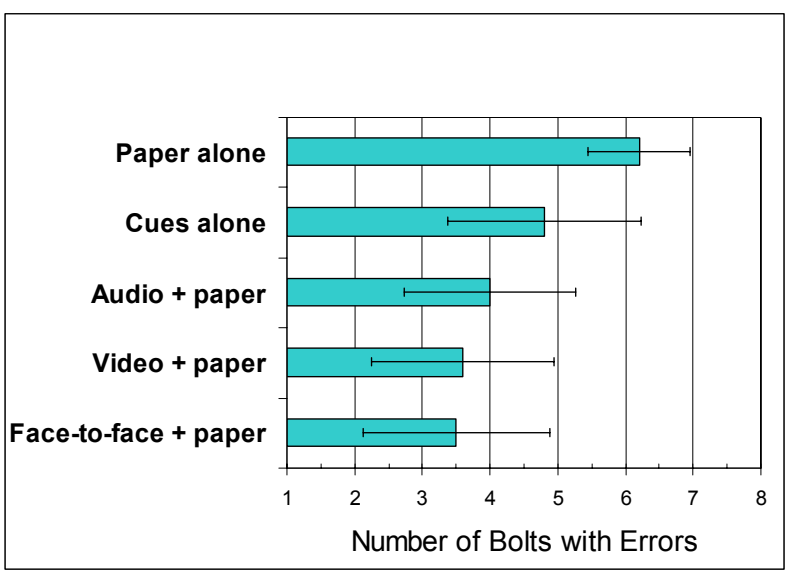

Figure 2. Mean number of completed bolts with errors (out of eight bolts) in each briefing modality.

As shown in Figure 3, participants in the paper alone condition produced more written communication acts (includes words and diagrams) $(M=390)$ than all of the other conditions $(M S=264.9,255.2$, and 242.9 respectively) $(M S=$ $46756.2, F(3,27)=12.75, p<.001)$. This indicates that participants in this condition spent their handover preparation time, which was equal for all conditions, producing lengthier and more complete written handover notes. Nonetheless, these lengthier written notes did not reduce errors as much as use of the other modalities. 


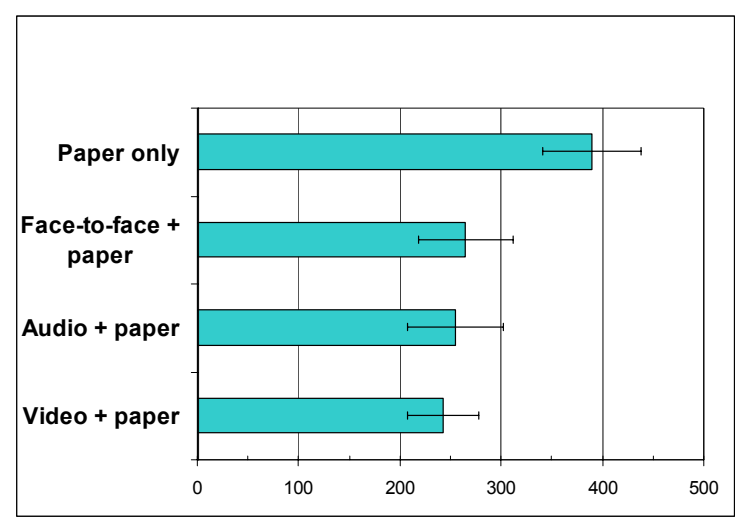

Figure 3. Mean number of written communication acts

as

a function of briefing modality.

\section{Ease of Giving and Receiving Handovers}

Figure 4 shows the ratings of the ease of both giving and receiving handovers. In general, participants felt it was easier to give than receive a handover. Paired t-tests (two tailed) show significant differences in ease of giving vs. receiving handovers in the following conditions: face-to-face $(p<.01, t$ $=2.9, d f 48)$ and audio $(p<.01, \mathrm{t}=2.75, d f 49)$.

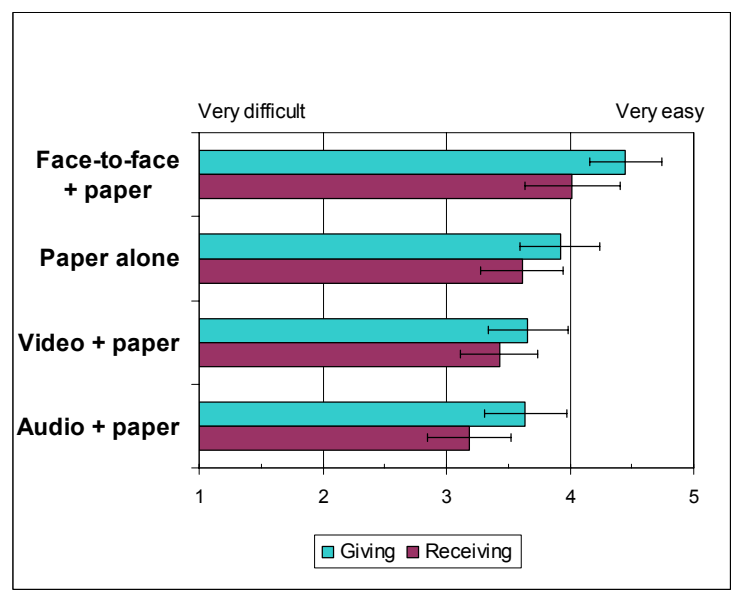

Figure 4. Mean ratings of ease of giving and receiving handovers on a 5-point Likert scale as a function of briefing modality.

Participants rated the face-to-face condition as the easiest in which to give information, with all other conditions being rated similarly. $(M S=6.38, F(3,144)=7.53, p<.001)$. Both the face-to-face and the paper alone condition were rated as significantly easier in which to receive information than audio supported handovers $(M S=6.1, F(3,144)=5.29, p<.01)$. Handling the audio and video technologies proved to be difficult for some participants; more training might have increased the ease of giving and receiving handovers using audio and video support.

\section{Rankings of Handover Modalities}

The participants were asked to rank order the various types of handovers they would set in place if they "were in charge of choosing a method for communicating between shifts for a high risk industry such as aviation maintenance." Figure 5 shows these rankings, with the higher number indicating the method the participants most preferred.

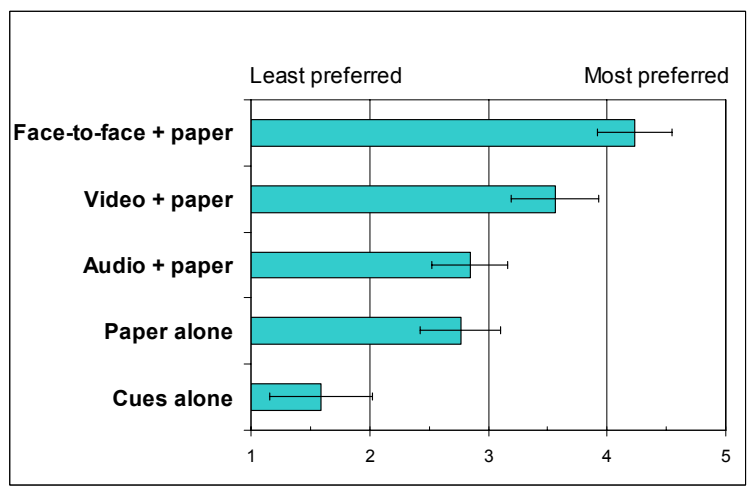

Figure 5. Participants' rank ordering of methods they would prefer if they were in charge of shift handovers in a high risk industry. The higher numbers indicate higher preference.

As can be seen, the most preferred condition was the face-toface handover support. The second most preferred was video support. Less preferred were the audio supported and the paper alone conditions. Least preferred is the cues alone condition (no materials provided). (Friedman test Chi-Square $=83.72, d f=4, N=49, p<.001$. All comparisons are significantly different from each other at $p<.05$ except paper alone vs. audio supported.

\section{DISCUSSION}

All of the support modalities - face-to-face, video and audio - reduced errors over paper alone handovers. Face-toface supported handovers were rated as the easiest to give and receive compared to other support modalities. Face-to-face support of paper handovers was also ranked as being most effective; however, video support was also ranked higher than paper alone.

As predicted, the addition of face-to-face communication to a handover resulted in significantly fewer errors, when compared with handovers based on paper alone. Perhaps surprisingly, the audio or video supported handovers produced only a slight non-significant increase of errors over the faceto-face condition. This result suggests that the benefits of face-to-face communication in this study were related to the transfer of non-verbal cues, rather than the possibilities for questioning and feedback afforded by synchronous communication. Analysis of video results showed that the receivers of face-to-face handovers did use the opportunity to ask questions (an average of 3.7 per handover). However, the 
givers of handovers were less likely to take advantage of the opportunity to confirm that information was being received and comprehended by the recipient, as they asked an average of only 1.0 questions per handover. It is possible that training in effective face-to-face handovers would have resulted in better face-to-face handovers. Such training could include having the recipient of the information repeat the information and having the giver of the information ask whether the recipient understands the information.

In all cases, participants considered it was easier to give than to receive a handover. This implies that the complications attending handovers affect the receiver more acutely than the giver, who of course is about to depart and has no further responsibility for the task. Anecdotally, several participants reported that the experience of receiving a handover, particularly a poor handover, gave them insights that helped them to give more effective handovers.

A somewhat surprising finding was that the "cues alone" condition did not produce as many errors as expected. This condition was intended as a control, to provide a performance baseline in the absence of inter-shift communication. It appeared that when other forms of communication were not permitted, participants were able to transmit some task information to the incoming shift via cues such as the placement of materials on the workbench.

In conclusion, the overall support for face-to-face handovers found in this study is in line with the literature on best practices in shift handover. Judging by the reduction of errors provided by the video and audio support conditions over the paper alone condition, it appears that some of the rich aspects of personal communication were also captured by video and audio technologies. Hence these technologies may be helpful in reducing shift handover errors when it is not possible to give a face-to-face handover.

The experimental task developed for this study was effective in eliciting errors in a laboratory setting and was sensitive to differences in shift handover modalities. The task has potential for use in future studies examining inter-shift communication.

\section{REFERENCES}

Baltes, B. B., M. W. Dickson, M. P. Sherman, C. C. Bauer, \&and J. S. LaGanke, (2002). Computer-mediated communication and group decision making: A metaanalysis. Organizational Behavior and Human Decision Processes, 87, 156-179.

Cullen, W. D. (1990). The public inquiry into the Piper Alpha Disaster. London: Stationary Office Books.

Della Rocco, P., Cruz, C., \& Clemens, J. A. (1999). Operational errors/deviations and shift work in Air Traffic Control. DOT/FAA/AM-99/2. Springfield, Virginia: NTIS \#199990310-004.
Department of Energy (1998). DOE Standard: Guide to good practices for operations turnover. DOE-STD1038-93, updated December 1998, U. S. Department of Energy, Washington, D. C. 20585

FAA (2001). Air Traffic Control Manual, Appendix D. 7110.65M. Available at www.hf.faa.gov

Eiff, G., Lopp, D., Nejely, D., \& Vice, M. (2001). Improving safety and productivity through a more effective maintenance shift turnover. Available at http://hfskyway.faa.gov

Grusenmeyer, C. (1995). Shared functional representation in cooperative tasks - The example of shift changeover. International Journal of Human Factors in Manufacturing, 5, 163-176.

Hopkin, D. V. (1980). The measurement of the air traffic controller. Human Factors, 22, 547-560.

Knapp, M. L. (1995). Essentials of nonverbal communication. N.Y.: Holt, Rinehart, \& Winston.

Lardner, R. (2000). Effective shift handover. In M.Cottam, D. Harvey, R. Pape, \& J. Tait. (Eds.), Proceedings of ESREL 2000, SaRS and SRA, 1, pp. 413-422. Rotterdam, The Netherlands: A.A. Balkema.

Leavitt, H. J., \& Mueller, R. (1962). Some effects of feedback on communication. In A. P. Hare, E. F. Borgatta, \& R. F. Bales (Eds.), Small Groups: Studies in Social Interaction. New York: Knopf.

National Transportation Safety Board. (1992). Aircraft Accident Report: Britt Airways, Inc. Continental Express Flight 2574, In-flight Structural Breakup, EMB-120RT, N33701, Eagle Lake, Texas, September 11, 1991. (NTSB/AAR-92/04, PB92-910405), Washington DC: Author.

Parke, B. \& Kanki, B. (2008). Best practices in shift turnovers: Implications for reducing aviation maintenance turnover errors as revealed in ASRS Reports. International Journal of Aviation Psychology, $18,72-85$.

Patterson, E. S., \& Woods, D. D. (2001). Shift changes, updates, and the on-call architecture in space shuttle mission control. Computer Supported Cooperative Work, 10, 317-346.

Reason, J. (1997). Managing the risks of organizational accidents. Aldershot: Ashgate.

Stager, P., \& Hameluck, D. (1988). Factors associated with air traffic control operating irregularities: An analysis of fact finding board reports. Technical Report TP 9342E. Ottawa, Ontario: Transport Canada.

Wainfan, L. \& Davis, P. K. (2004). Challenges in virtual collaboration: videoconferencing, audioconferencing, and computer-mediated communications. Santa Monica: Rand Corporation. 